\title{
inventions
}

Article

\section{The Entropy Model for Sustainability Assessment in Industrial Ecosystems}

\author{
Tatyana Tolstykh ${ }^{1}$, Nadezhda Shmeleva ${ }^{2}$, Yulia Vertakova ${ }^{3,4}$ and Vladimir Plotnikov ${ }^{5, *}$ (i) \\ 1 Industrial Management Department, National University of Science \& Technology (MISIS), \\ 119049 Moscow, Russia; tolstyh.to@misis.ru \\ 2 Economics Department, National University of Science \& Technology (MISIS), 119049 Moscow, Russia; \\ nshmeleva@misis.ru \\ 3 Financial University under the Government of the Russian Federation, Kursk Branch, 305016 Kursk, Russia; \\ vertakova7@ya.ru \\ 4 Regional Economy and Management Department, Southwest State University, 305004 Kursk, Russia \\ 5 General Economic Theory and History of Economic Thought Department, St. Petersburg State University of \\ Economics, 191023 St. Petersburg, Russia \\ * Correspondence: plotnikov_2000@mail.ru; Tel.: +7-911-949-1321
}

Received: 11 October 2020; Accepted: 5 November 2020; Published: 7 November 2020

check for updates

\begin{abstract}
The aim of this paper is to address the gap in the academic literature towards the development of methodological approaches to the industrial ecosystem sustainability assessment. This study was focused on the industrial ecosystems formed based on an entropy model and implementing the principles of complex systems. This article systematizes the problem of applying the ecosystem approach to cross-industry interaction. A contribution to the literature was achieved by providing a systemic perspective on the sustainable industrial process. In this paper, we develop the methodological foundations to improve the understanding of integration processes' influence on the industrial ecosystem potential. For a relevant analysis of industrial ecosystem potential, the existing patterns of system functioning were taken into account, including entropy equilibrium and the Harrington model. We illustrate our assumptions with an empirical case study of the National University of Science and Technology (NUST) "MISIS" ecosystem-“"Green technologies for resource conservation" (Russia), with an assessment of ecosystem sustainability through the actors' collaboration level. The propositions arising from this analysis provide information to help academics, policymakers, government, and individual enterprises with a more adequate understanding of the practical mechanisms and tools that help trigger the self-organization and sustainability of the industrial ecosystems.
\end{abstract}

Keywords: ecosystem; entropic balance; resource conservation; sustainable development; green technologies; waste recycling; model; innovation; industry

\section{Introduction}

Technological, digital, environmental, and political trends swiftly and universally have covered all social and economic processes. Emerging fundamental challenges change approaches to the development of socio-economic systems towards:

(1) Changing the paradigm from "human for economics" to "economics for human".

(2) Transformation of the environment through the triad of nature, technology, and culture.

(3) Transformation of the new world order as a result of the humanitarian and technological revolution [1-3]. 
Market participants are forced not only to respond to challenges, but also to predict them. This requires a search for new behavioral models and new approaches to strategizing. This situation is especially relevant for industrial enterprises, which have a significant inertial log within their industry specifics. A fundamentally different type of resources is coming to the forefront intellectual, changing the ratio of competitive advantages in the market. It is practically impossible for enterprises not only to maintain competitive leadership, but also simply to survive in the present realities alone, which entails the need to change the models of interaction between organizations [4-6].

The search for organizational and managerial models that provide innovative sustainable development through synergistic symbiosis has been going on for several decades. These models include clusters, industrial networks, and industrial and eco-industrial parks. Each of these models has its own advantages and limitations. The main limiting point of network and cluster models is that horizontal synergistic interaction between participants is subject to vertical management from above. The management system can be either a state structure or a large enterprise, building network relations with other enterprises for their interests. Elements of the management vertical initially violate the principles of harmonization and balanced development of individual participants, since the interests and priorities of the governing body do not always coincide with the interests of other participants. In Antifragility: Things That Gain from Disorder, Nassim Nicholas Taleb [7] defined large vertical systems as "fragile" in terms of the risks of making managerial decisions. In contrast to such systems, the combination of companies on partnership terms without vertical administration is "anti-fragile" with respect to internal and external challenges.

One of the most relevant discussed organizational and economic models of socio-economic development are ecosystem models [8-16]. The ecosystem model allows for forming a special friendly environment for enterprises through a voluntary partnership for the generation and implementation of innovative projects in various fields. It allows the ecosystem participants to be open to external challenges through the integration of resources, knowledge, information, technologies, competencies, ensuring the principles of their sustainable development.

The authors consider that an ecosystem is the association of independent actors based on the principles of self-organization and self-development to achieve their internal goals, which correspond to the requirements and needs of the society. The actors are united in ecosystems according to their functional target interests, forming numerous sectoral, entrepreneurial, innovative, business, and other ecosystems [17-19]. This approach allows for developing the open innovation perspective through the principles of the ecosystem, when all participating companies, regardless of their size and type of activity, benefit from networking and collaboration.

Despite the increased interest of the scientific community in the problem of the formation and development of industrial ecosystems, one should admit the weak methodological elaboration of this theory, which complicates its application in practice.

This article aims to develop methodological approaches to assessing industrial ecosystems sustainability, taking into consideration the new paradigm of socio-economic development. The subject of the research is innovative industrial ecosystems. The article systematizes the problem of applying the ecosystem approach to cross-sectoral interaction. The main research question was how to operationalize the processes of self-organization in the industrial ecosystem without an external governing body and to ensure ecosystem sustainability.

The article is organized as follows. Section 2 provides a theoretical overview of the industrial ecosystem, related concepts, and approaches. In this section, we analyze the sustainability perspective of ecosystems with specific reference to the emerging perspectives on what the role and objective of sustainability assessment should be. Section 3 is devoted to the theoretical foundations of our research, introducing our conceptual assumptions and chosen approaches. Section 4 presents a new methodology for the assessment of industrial ecosystem sustainability using the theory of conflictology, entropy, and Harrington models. Section 5 further specifies how to operationalize the assessment using the described methodology. We demonstrate our methodology by the example of an empirical case study 
of the National University of Science and Technology (NUST) "MISIS" ecosystem. Section 6 highlights the key findings of the study and presents the theoretical contribution and practical significance of the study. In this section, we also discuss propositions arising from the conducted analysis to bring out the features of the sustainability of industrial ecosystems and their implications in terms of actor's collaboration. Finally, in Section 7, some limitations of the research and points for further discussion are proposed, specifically regarding our concerns on the possibility of performing a more accurate sustainability assessment for different types of ecosystems.

\section{Literature Review}

One of the most discussed models of enterprises' innovative development is the formation of industrial ecosystems $[8,20]$. Over the past decade, the concept of the ecosystem has become so popular in the discussion that we agree with the author [20], who believe this is the reason for unclear and incorrect formulations. From our point of view, sometimes there is a substitution of terms: the ecosystem is understood as a network innovation cluster or looks like a trinity of major players: University-business-state [21]. According to Bruns [22], the term "ecosystem" describes the effects of symbiosis in production, associations of firms (business ecosystems, entrepreneurial ecosystems), or other activities (services, innovations, and digital ecosystems). As a result of ambiguity in terminology, the scientific literature uses "business ecosystems" [23], "innovation ecosystems" [24], "digital ecosystems" [25], "University ecosystems" [26], or "financial ecosystems" [27]. In [28], an ecosystem is a system consisting of actors and dynamic processes in which they participate.

We believe the most comprehensive definition of the innovation industrial ecosystem is that proposed by Granstrand and Holgersson (2020). According to the authors, such an ecosystem is an evolving set of actors, activities, and artifacts, and the institutions and relations, including complementary and substitute relations, that are important for the innovative performance of an actor or a population of actors [29]. The researchers identify two conceptual approaches to the ecosystems [30]. According to the second approach, an ecosystem is a system of interconnected technologies, cooperating and competing firms offering related goods and services [31,32]. In parallel, the theory of industrial ecosystems is actively evolving. Kleiner defines industrial ecosystems as localized socioeconomic formations achieving sustainable development through the circulation of resources in objective, environmental, process, and project subsystems [33]. In [30], the industrial ecosystem is defined as a set of components made by the product platform's owner and enhancements made by independent companies from the periphery. In turn, the ecosystem platform is defined as a network of innovations, increasing the platform's value $[34,35]$. Several terms related to the industrial ecosystems that have appeared in the literature, stressing their interdisciplinary nature, including the industrial symbiosis, (eco-) industrial parks, and (eco-) industrial networks. We further specify these notions.

We agree with the position of the authors who believe that ecosystems are not a simple integration of individual participants, but the formation of an intellectual environment between actors $[12,13]$. In this case, the goal of collaboration ecosystem actors can be digital platforms, new technologies, materials, innovative projects, or specific research organizations that integrate actors around themselves through joint relationships based on the exchange of knowledge, competencies, and information $[20,30,36]$. An ecosystem is, first of all, a voluntary association of a certain number of actors to implement projects, the digital transformation of business processes, and the development of new materials or technologies [20,29].

The industrial enterprises are often integrated into the processes of initiation and implementation of various projects, which, from our point of view, can be considered as the initial stage of ecosystem formation.

We propose to use the concept of entropy as a measure of ordering and evaluation of the degree of interaction. The entropy of a system is a way of the mutual arrangement of system elements in an equilibrium state [37]. An ecosystem involves a constant and intensive exchange of energy between 
actors (information, knowledge, technologies, and competencies), which defines an ecosystem as "open" or "dissipative". One of the defining principles of ecosystem formation is self-organization. In the theory of synergetics [38], self-organization is understood as the emergence of stable States of organization and manageability without external influence. Creating conditions for self-organization may by controlling the order of the system, adding useful energy to it, which leads to an increase in negative entropy (negoentropy) [38]. As a result, reducing the entropy of the system. The greater the entropy of systems, the less is it ordered. In complex systems, the information component of the process, rather than the material one, comes to the fore, considering not only the qualities of actors, but also the connections between them, as discussed in [7]. The self-organization of complex systems based on the entropy approach was studied by Kleyner [35], Haken [37], and Prangishvili [39]. However, the entropy approach is used in the analysis of physical, social, or information systems. There are few works devoted to the use of the entropy approach for evaluating large industrial complexes or symbioses, which makes the research relevant.

\section{Conceptual Framework}

The cooperation of ecosystem actors is based on network partnership principles and cognition as a principal mechanism for achieving strategic goals by the actors $[40,41]$. The ecosystem operates at a basis of "energy" exchange between business, industry, scientific community, and government. By "energy" we mean information, knowledge, technologies, or key resources. Ecosystem self-organization occurs as a response to digital challenges, ecological and industrial trends in the forms of new innovation projects, products, digital platforms, and technologies. The ecosystem model is the evolution of cluster, network, and infrastructure communication models (Table 1). It brings together best cooperation practices with ecosystem-specific features crucial in terms of new technological challenges [17-19].

Table 1. Comparative analysis of cluster and ecosystem approaches.

\begin{tabular}{|c|c|c|}
\hline Comparison Criterion & Industrial Clusters & Industrial Ecosystems \\
\hline Coordination Mechanism & $\begin{array}{l}\text { Decision of federal, industry, } \\
\text { or municipal authorities }\end{array}$ & Self-organization \\
\hline Cooperation Target & $\begin{array}{l}\text { Increasing the competitiveness of } \\
\text { an industry or region }\end{array}$ & $\begin{array}{l}\text { Initiation and implementation of } \\
\text { digital innovation or unique product }\end{array}$ \\
\hline Unification boundaries & Geographic or industry & Cross-industry, territorial \\
\hline Matching Criteria & Stages of the production process & $\begin{array}{l}\text { Life cycle stages of projects, products, } \\
\text { technologies }\end{array}$ \\
\hline $\begin{array}{l}\text { Relationships between } \\
\text { participants }\end{array}$ & $\begin{array}{l}\text { Internal competition and } \\
\text { cooperation }\end{array}$ & Cooperation and partnership \\
\hline $\begin{array}{l}\text { Possibility to include or } \\
\text { exclude actors }\end{array}$ & Restriction on inputs and outputs & High level of openness \\
\hline Controllability & $\begin{array}{l}\text { government bodies at federal or } \\
\text { regional levels }\end{array}$ & Pacemaker \\
\hline
\end{tabular}

Self-organization, lack of managerial institutions, and intellectual environment are the basic differences between the industrial ecosystem and clusters or networks. However, self-organization does not suppose chaotic and spontaneous integration. "Pacemaker" is the center of the ecosystem that coordinates and balances the actions of all other actors. An actor, technology, project, or platform may act as a "pacemaker". Actors of the industrial ecosystem include industrial companies, techno-parks, start-ups, venture funds, engineering companies, government institutions, funds, financial structures, and other actors whose interests overlap with the strategic goals of the ecosystem, which are defined by the pacemaker. In terms of the new industrial revolution, we may highlight the following principles for industrial ecosystems establishment:

- transboundary ecosystem processes;

- self-organization, self-regulation, and self-development; 
- joint development and use of information, innovation, and intellectual resources;

- continuous flow of successive projects (one project initiates the following projects' implementation);

- agility and flexibility to external challenges;

- $\quad$ project- and client-orientation;

- diversity of actors and network organization design;

- collaboration based on partnership, trust, cooperation, and mutual help;

- balance between goals and objectives of actors;

- knowledge circulation;

- resources conservation priority;

- maintaining and development of each actor's potential.

Each actor, being included in the ecosystem, is overgrown with connections with other actors. Therefore, the number and strength of connections are the basis for ecosystem sustainability. The behavior of the ecosystem depends on the behavior of many subsystems (actors), including relationships between them [36].

We consider that an industrial ecosystem is an open and self-developing system of actors network equality, self-organizing as a result of the collaboration between actors and the exchange of energy. The energy in an ecosystem is new knowledge, technology, information, or unique resources.

Industrial enterprises, ecosystems, engineering enterprises, startups, venture companies, and funds can work as actors of the industrial ecosystem [42]. At the same time, the actor can play different roles, participating in projects, for example, a customer, a provider of unique resources, a stakeholder, a developer, etc. The keyword in defining an ecosystem is self-organization, which occurs as a result of the emerging needs of market participants, shaped by digital and industrial challenges, and is implemented in the form of innovative projects, creating a new product, developing digital platforms, creating new technology, etc.

Universities that accumulate and create national and worldwide expertise and cooperate with many companies from the industry can act as integrators involving new actors and enabling collaboration, as well as knowledge and information exchange. An integrator also acts as a pacemaker and a project office. When new members are involved and knowledge is being exchanged, actors start to generate ideas and initiate projects. That provides the principle that ecosystem projects have no time limits.

The sustainability of an industrial ecosystem is associated with the entropy concept. According to Bailey (Social Entropy Theory) and Forsé (L'Ordre Improbable. Entropie et Processus Sociaux) [43], the development of systems is characterized by instability and non-equilibrium as a constant fluctuation between organization and disorganization. Ecosystems are systems that are characterized by instability and disorganization. The ecosystems are created on the principles of self-organization when there is no external management system. The idea (pacemaker) of ecosystem formation is, for example, a new project, which is the response of economic actors to technological challenges acting as chaos [17]. It is chaos for complex disorganization systems, being ecosystems, that ensures their openness, and acts as an incentive for development. Negative entropy characterizes the development of a system and its openness. The greater the entropy is, the stiffer the structure of the system is, and the more unstable the system is from the standpoint of external influences (fluctuations).

Entropy stability is present if the order and organization within the system balance the disorder and disorganization of interactions between actors. It is here when a system can be called sustainable. Each ecosystem strives for entropy equilibrium. The more complex the ecosystem structure is, the larger it is, and the less predictable its behavior is. The sustainability of the ecosystem is ensured by the diversity and complexity of the relationships of the participants included in its composition. Systems of high sustainability can perceive significant effects without substantially changing their structure, that is, without going beyond the equilibrium state. Moreover, the concept of sustainability is not equivalent to the concept of stability, since attention is paid to the invariability of the structure here. Systems of an invariable structure can be called "fragile" by analogy with technical systems. An assessment of 
ecosystems in terms of sustainability is determined, as a rule, by the variability of the environment: Under stable conditions, systems are prone to a higher internal organization; under variable conditions, the preference is given to disorganization.

\section{Research Methodology}

The methodology for assessing the effectiveness of industrial ecosystems is related to estimating stability relations level between actors. An ecosystem is a complex open system, as it interacts with the external environment by transmitting energy in the form of information, knowledge, and competencies. Complex systems are characterized by processes of self-organization, when new actors are connected to the ecosystem and new connections are formed, and processes of disorganization, when connections are destroyed for one reason or another, and the actor leaves the ecosystem. The external environment for an ecosystem is the society, territories, and industry that interact with the ecosystem in pursuit of their goals. Since the ecosystem is a combination of both actors, relationships between them, and processes, it is impossible to predict the state of the ecosystem and assess its stability by observing and studying each element of the system separately.

The behavior of an ecosystem depends on the external environment, on the behavior of actors, and their interaction with each other. Entropy is a quantitative measure of disorder in a system. The greater the entropy of the ecosystem state, the more ways it can be implemented between actors, the less ordered it is, and the more self-organized the actors of this ecosystem are. In other words, an increase in entropy means an increase in the degree of freedom of the actor from external control, and, consequently, an increase in its self-organization and, as a result, responsibility for its own sustainable development.

The authors propose using the entropy method [39] and Harrington's desirability technique [44] to assess the strength of the connection between actors and the sustainability of the ecosystem. In accordance with the entropy theory the actors $\left(A_{i}\right)$ of ecosystem $E$ across $D_{i}$-a set of goals and potentials that characterize a given participant $\left(d_{i r}\right)_{1}^{R}$, then $\left\{D_{i},\left(d_{i r}\right)_{1}^{R}\right\}$ will represent the system $A_{i}$. This is described by Formula (1):

$$
A_{i}=\left\{D_{i},\left(d_{i r}\right)_{1}^{R}\right\}, i=1,2, \ldots, n
$$

For example:

$A_{1}$ - one of the actors whose goal is to implement a project of the digital transformation of a business process - a set of $D_{1}$ targets.

$A_{2}$-another actor, whose goal is, for example, a project to develop a unique process control sensor-a set of $D_{2}$ targets.

At the same time, achieving the internal goal of each actor $A_{i}$ will depend on the implementation of some management trajectory and the eco-environment in which the system operates. The internal transformations' effectiveness depends on the behavior and the connections between actors in the ecosystem. The influence of actors on ecosystem sustainability depends on

(1) the potential of the actor, that is, the availability of unique technologies, resources, and competencies;

(2) the extent of the actor's relationships with other actors.

On the one hand, the more actors an ecosystem includes, the higher its synergistic potential and the more sustainable it is to external challenges. On the other hand, many relationships entail the risks of interest conflicts.

In order to assess the level of connections stability between actors, evaluate them by representing their interests as a numerical domain, in which for all $\left(d_{i r}\right)_{1}^{R}$ the condition given by Formula (2) is satisfied:

$$
\Sigma\left(d_{i r}\right)=1,
$$


where $p$ is a given function that reflects the position that some target indicator $k$ of the $A_{i}$ actor is preferable for the ecosystem than the indicator $l$ of the $A_{j}$ actor. This is given by Formula (3):

$$
d_{i k}>d_{j l}
$$

In other words, the $p$ function is a normalized measure of the ecosystem targets. As a function $p$, you can use the probability that the $A_{i}$ actor of the ecosystem implements the $d_{i k}$ goal, i.e., $p\left(d_{i k}\right)$. Then $p=m_{i} / N$, where $N$-the number of ecosystem goals, and $m_{i}$ is the number of shared goals for actors.

Each actor has its own goal, which is preferable to the goals of other actors, but from the standpoint of the ecosystem. The priority of the projects implementation within the ecosystem is influenced by the integral indicators, reflecting the time cycle of the project (the shorter the cycle, the more preferable), the speed of implementation, the uniqueness of the project, the degree of importance of the project for other actors, etc.

However, it is not possible to describe the sustainable behavior of an ecosystem only from a quantitative approach to determining ecosystem targets. We used the concept of ecosystem entropy behavior. The entropy of ecosystem behavior $E$ considered as a qualitative characteristic of the system, reflecting the level of balanced utility of system projects based on the analysis of the demands for these projects for all actors [38]. By the degree of balance of the usefulness of projects we mean the uniformity of the project's importance for all actors. If one project is more important than the others, then the balance of usefulness of this project is low. For example, creating a digital project office that allows each actor to effectively interact with other actors in the implementation of their goals has a high balance level. The implementation of private actors' projects is characterized by a lower level relative to the ecosystem.

We present the category of predictability or unpredictability of ecosystem behavior. If the targets of actors are highly organized or equivalent, then it is difficult to formulate a priori assumptions about the priority of projects, that is, which project will be initially implemented by the system, in other words, the behavior of the system is difficult to identify-the relationship between the categories: organization $\sim$ unpredictability; disorganization $\sim$ predictability. The concepts of organization and unpredictability or disorganization and predictability are not identical; they only correspond to each other. The entropy of ecosystem behavior, as a category of organization (or disorganization), can be viewed as a category of unpredictability with respect to the environment external to the ecosystem or its internal environment (Figure 1).

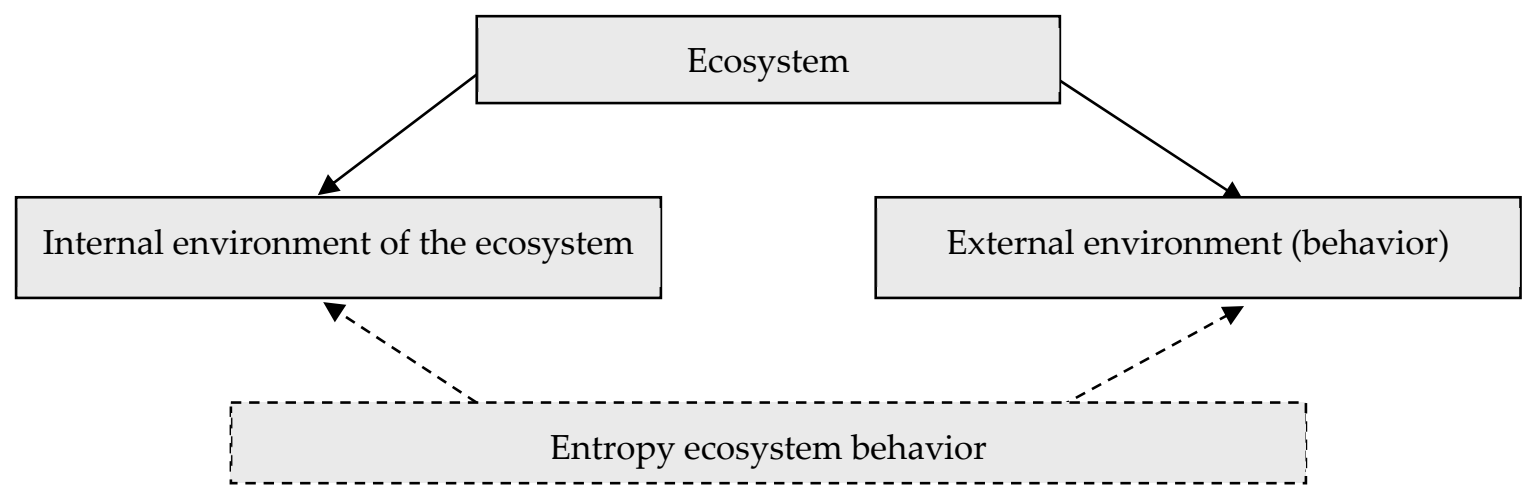

Figure 1. Interpretation of an ecosystem entropy behavior.

A measure of ecosystem entropy $E$ or imprecise entropy is some combination of the quantitative characteristics of actors $A$, i.e., as a function of the quantitative characteristics of targets. If the measure of entropy of the behavior of the actor $A_{1}$, denote $E\left(A_{1}\right)$, it can be represented by Formula (4):

$$
\left(A_{i}\right)=E\left(p_{1}, \ldots, p_{n}\right)
$$


where $p\left(d_{i k}\right)=p_{i}, i=1,2, \ldots, n$.

Thus, we obtain a uniquely defined measure of the entropy of ecosystem behavior [3]. Entropy is quantified using Formula (5):

$$
E\left(A_{i}\right)=-\Sigma p\left(d_{i k}\right) \log _{2} p\left(d_{i k}\right)
$$

Entropic equilibrium or stability exists when disorder and disorganization balance order and organization, and the system becomes stable. Any deviation from the point of balance in any direction causes either excessive orderliness and organization, or excessive disorder and disorganization. Each ecosystem strives for entropic balance $\left(E_{p}=E\right)$. This phenomenon is called the regularity of entropic equilibrium, or the increase and decrease of entropy, in an open system [39].

Based on the axioms, the more complex the structure of the ecosystem, the larger it is, the less predictable its behavior is, and, conversely, the less organized the set of target settings of the ecosystem, the more predictable its behavior will be. The concept of entropy of ecosystem behavior is a category that allows describing the dependencies of two actors included in its structure. According to system theory, each system is part of another system, but of a higher level.

Each actor in the ecological environment has his own environment. That is $A_{j}$ may also include an actor in its environment $A_{i}$, which allows you to define the categories of the dependence of the actor on his environment or the dependence between two actors in the ecosystem. The possibility of realizing the goals of an individual actor is his internal behavior, through which the actor manifests himself in the environment of the ecosystem. This capability is a qualitative category, but it has characteristics that qualify it in relation to the environment.

We propose to consider the environment of the actor $A_{i}$ is a subsystem of the actor's environment $A_{j}$. Then, under the possibilities of implementing the target settings of the actor $A_{i}$ in relation to the environment $A_{j}$, we will understand the possibilities of implementing the target indicators $A_{i}$ under the assumption that the target indicators of the actor $A_{j}$ are realized.

The actor dependency concept $A_{i}$ from the actor $A_{j}$ is a relative category that characterizes the relationship between the external environments of systems $A_{i}$ and $A_{j}$ (Figure 2).



Figure 2. Interpretation of two systems behavior.

If two actors can be said $A_{j} \rightarrow A_{i}$, then the actor $A_{j}$ is called dominant, and the actor $A_{i}$-addicted. Figure 2 shows that the relationship of the dependence that can be separated from the entropy of the actor dominating in the dependence $A_{j} \rightarrow A_{i}$, and the less predictable the behavior of the dominant system, the stronger the dependence and vice versa. If the behavior of the dominant actor in the ecosystem is predictable, then the position of the dependent actor is more favorable, and the dependence is weaker than the case when the behavior of the dominant actor is unpredictable. 
Under the magnitude $Z\left(A_{j} \rightarrow A_{i}\right)$ we will understand the absolute measure of dependence $A_{j} \rightarrow A_{i}$, defined by the Formula (6):

$$
Z\left(A_{j} \rightarrow A_{i}\right)=E\left(A_{j}\right)-E\left(A_{i} \mid A_{j}\right)
$$

The normalized measure of dependence $A_{j} \rightarrow A_{i}$ has the following properties:

- $\quad$ equal to zero if the system $A_{j}$ does not depend on the system $A_{i}$.

- equal to 1 (maximum value) when the dependence is maximum, i.e., when any target indicator of the system $A_{i}$ is uniquely determined by the behavior of the system $A_{j}$.

- $\quad$ takes values from the interval $(0,1)$.

Determining the measurement of the dependence of actors, one can proceed to assess the environment of the ecosystem as a whole. We believe that ecosystem participants can perform different roles in the system, but each actor can simultaneously or alternately play several different roles, depending on different life cycles of projects being implemented or the life cycle of the ecosystem. Then we considered the role as a part of the actor's behavior corresponding to a specific dependence. Thus, the actors of the ecosystem form subsystems. A number of these subsystems can be associated with a function for all actor's pairs that satisfy certain conditions:

- $\quad$ an actor is independent only from himself, two actors are always dependent.

- $\quad$ if there is a dependency $A_{j} \rightarrow A_{i}$, then the inverse relationship equally exists $A_{i} \rightarrow A_{j}$.

- $\quad$ an actor $A_{m}$ depending on $A_{i}$, then dependence $A_{m}$ on $A_{i}$ will not decrease if "inserted" $A_{j}$ in relation to the relationship between $A_{m}$ и $A_{i}$.

These conditions can be formalized as follows:

1. $D\left(A_{j} \rightarrow A_{i}\right)=0 \Leftrightarrow A_{j}=A_{i}$.

2. $D\left(A_{j} \rightarrow A_{i}\right)=D\left(A_{i} \rightarrow A_{j}\right)$.

3. $D\left(A_{i} \rightarrow A_{m}\right) \leq D\left(A_{i} \rightarrow A_{j}\right)+D\left(A_{j} \rightarrow A_{m}\right)$.

The dependence between the actors is defined as the contradiction between the needs and the possibilities for the implementation of the target settings $A_{i}$ in the ecosystem environment.

Considered entropy approach assumes the different openness of actors in the ecosystem. The higher the openness level, the higher the readiness for self-organization at all levels of decision-making. This leads to the greater interest of the actor in developing their potential through the implementation and promotion of various projects. An actor's interest in development is reflected in the interaction with other actors, which leads to the sustainability of the ecosystem.

Then the following statements are true for each actor:

- the trajectory of the behavior of the actor $A_{i}$ is determined by the difference between the need and the possibilities to achieve their goals, considering the dependence on other actors.

- the trajectory of the behavior of the actor $A_{i}$ is influenced by the tendency to continue, fulfill, or accept such roles in the ecosystem, which, on the other hand, will reduce his dependence on other actors and, increase the dependence of other actors on the actor $A_{i}$.

- dependence, as a contradiction between the necessity and the possibilities of realizing the goals of the actor $A_{i}$, can change in the event of changes either in the actor's capabilities, or in the event of his adjusting his target indicators.

The more actors are included in the ecosystem and the more connections it includes, the fewer management trajectories in which the dependencies of actors are minimal. Moreover, even if the actor $A_{i}$ wants to choose a managerial decision that reduces his dependence on another actor $A_{j}$, it may turn out that some actor $A_{k}$ forces $A_{i}$ to make a completely different decision, which corresponds to the resulting even greater dependence. An attempt to transform the needs of achieving the goals of one actor into the possibility of achieving the goals of another actor will be called the conflict of the ecosystem environment. 
From this point of view, conflict is the actions of actors against dependence on other actors, and conflict action is behavior determined by dependencies. The conflicting relationship between the target indicator $\mathrm{m}$ of the actor $A_{i}$ and the target indicator $\mathrm{n}$ of the actor $A_{j}$ is formalized can be represented as $P\left(d_{i m}\right)<P\left(d_{i m} / d_{j n}\right)$.

Then the relationship of probabilistic cooperation is described as $P\left(d_{i m}\right)>P\left(d_{i m} / d_{j n}\right)$. The fulfillment of the target indicator of the actor $A_{j}$ decreases or increases the probability that the actor $A_{i}$ will reach his indicator $\mathrm{m}$. To identify and assess conflicts in an ecosystem, as a stochastic system, a quantitative approach is needed to assess conflict relationships. Since conflict is the degree of development of a contradiction arising from organization or disorganization, predictability or unpredictability, it is possible to use the concept of entropy as such a measure, which has the following properties:

- $\quad$ equal to zero if one trajectory is feasible and the others are impossible.

- $\quad$ maximum when all possible states are equally probable.

- $\quad$ addictive.

This approach allows you to define the structural dependencies of actors $A_{i}$ и $A_{j}$, namely the proportion of the relationship between conflict and cooperation. And then, by changing the set of possible target indicators of each actor by adjusting management trajectories, it is possible to achieve a change in the relative share of conflict in the overall dependence of actors, which will increase the stability of the ecosystem as a whole.

The presented methodology was tested on the example of the NUST «MISIS» ecosystem (National University of Science and Technology “MISIS" (Russia) ecosystem).

\section{Case: The Sustainability Assessment in the Industrial Ecosystems “Green Technologies for Resource Conservation"}

The entropy method is described in the methodological part of the article. The "Green technologies for resource conservation" ecosystem is of interest for assessing the ecosystem attractiveness and sustainability, as it is a cross-border, cross-sectoral, and dynamic ecosystem. In such an ecosystem, the actors are represented by different countries, industries, research centers, and the distribution of roles between them vary depending on the life cycle of ongoing projects and the ecosystem. The ecosystem's pacemaker is the idea of developing fundamentally new technologies and materials in order to improve the environment.

NUST "MISIS" takes part in innovative projects through a system of interaction and partnership with enterprises of various industries, international research centers, and laboratories. One of the strategic directions of the university's development is the formation of new competencies in the field of green technology engineering, as well as positioning NUST "MISIS" as a leader in the field of sustainable development in the raw materials and processing sectors.

As part of this direction, the University has created a multi-level ecosystem "Green technologies for resource conservation". Subject areas of the ecosystem:

1. Waste management of mining and processing of mineral raw materials.

2. Processing of chemical products and radioactive waste.

Projects implemented by this ecosystem:

Project 1. Development of a new generation of flexible and high-performance catalytic reactor systems based on structured catalysts (adsorbents) for the complex processing of natural and associated gases, as well as biogas using various processes.

Project 2. Development of technologies for the production and use of composite binders for the construction of transport and hydraulic structures with the use of large-tonnage waste from the extraction and processing of mineral raw materials.

Project 3. Development of an integrated innovative technology for the extraction and processing of mineral raw materials with underground waste isolation for solving state scientific and technological problems of energy and environmental safety. 
Descriptions of the actors of the ecosystem "Green technologies for resource conservation" are presented in Tables 2-4.

At the same time, the achievement of the internal goal of each actor $\left(A_{i}\right)$ will depend on the behavior of many other actors in the ecosystem and the connections between them. Each actor, being included in the ecosystem, is overgrown with connections with other actors; therefore, the number and strength of connections are the basis for sustainable development of the ecosystem.

The pacemaker acts as the center of intellectual attraction for actors in the ecosystem, which can be an actor, a technology, a project, and a platform [37]. The pacemaker ensures the exchange of cognitive energy balance and the coherence of all actor's interaction with each other (Figure 3).

Table 2. Characteristics of actors-researchers (National University of Science and Technology (NUST) "MISIS").

\begin{tabular}{|c|c|c|}
\hline Group of Actors $\left(A_{1}\right)$ & Objectives & Integral Indicators $\left(D_{1}\right)$ \\
\hline $\begin{array}{l}\text { 1. Laboratory "Nano Chemistry } \\
\text { and Ecology". } \\
\text { 2. MISIS Center for Resource-Saving } \\
\text { Technologies for Processing Mineral } \\
\text { Raw Materials. } \\
\text { 3. Industrial Technology } \\
\text { Engineering Center. } \\
\text { Innovative Scientific and Educational } \\
\text { Center "Romelt". }\end{array}$ & $\begin{array}{l}\text { Development of new technologies } \\
\text { for resource conservation and } \\
\text { processing of industrial and } \\
\text { man-made waste. } \\
\text { Commercialization of technologies. } \\
\text { R \& D. }\end{array}$ & $\begin{array}{l}\text { Total innovation index SII. } \\
\text { The level of digital maturity. } \\
\text { The share of unique } \\
\text { technologies in the overall } \\
\text { structure. } \\
\text { Research and development } \\
\text { costs. }\end{array}$ \\
\hline
\end{tabular}

Table 3. Characteristics of actors-partners of the ecosystem.

\begin{tabular}{ccc}
\hline Group of Actors $\left(\boldsymbol{A}_{\mathbf{2}}\right)$ & Objectives & Integral Indicators $\left(\boldsymbol{D}_{\mathbf{2}}\right)$ \\
\hline NRU MGSU. & Commercialization of technologies. & $\begin{array}{c}\text { The level of development of } \\
\text { cooperation between actors. } \\
\text { BSTU V.G. Shukhov. }\end{array}$ \\
$\begin{array}{c}\text { R \& D. } \\
\text { The number and cost of joint } \\
\text { University of the Basque. }\end{array}$ & $\begin{array}{c}\text { Implementation of complex } \\
\text { high-budget projects for large } \\
\text { industrial companies. }\end{array}$ & $\begin{array}{c}\text { projects in which ecosystem actors } \\
\text { are involved. }\end{array}$ \\
\hline
\end{tabular}

Table 4. Characteristics of actors-customers/consumers.

\begin{tabular}{|c|c|c|}
\hline Group of Actors $\left(A_{3}\right)$ & Objectives & Integral Indicators $\left(D_{3}\right)$ \\
\hline $\begin{array}{c}\text { Inter-RAO PJSC. } \\
\text { RusHydro PJSC. } \\
\text { Rosatom State Corporation. } \\
\text { Alrosa PJSC. } \\
\text { Novolipetsk Metallurgical Plant (Group of } \\
\text { Companies). } \\
\text { Federal Agency for Special Construction of } \\
\text { Russia (Spetsstroy of Russia). } \\
\text { Zabsibgazprom. }\end{array}$ & $\begin{array}{l}\text { Increasing competitiveness } \\
\text { and profitability through the } \\
\text { introduction of innovative } \\
\text { technologies and processes. }\end{array}$ & $\begin{array}{l}\text { Balanced financial result of the } \\
\text { actor.Correspondence of } \\
\text { resources to the strategic goals } \\
\text { of the actor. } \\
\text { Transfer of knowledge, } \\
\text { technologies, results within the } \\
\text { ecosystem. }\end{array}$ \\
\hline
\end{tabular}

The pacemaker of the first level of the ecosystem is the NUST "MISIS" Expert Council, which serves as an entry point for the formation of new ideas, competencies, technological solutions, and the initiation of projects to develop resource-saving technologies. The scientific laboratory of the University "Nano chemistry and Ecology" acts as a pacemaker at the second level of the ecosystem, providing cross-sectoral interaction and the integration of competencies within one scientific area. The laboratory serves as a single-entry point for industrial customers in the implementation of complex projects. The third level pacemaker is a large-scale interdisciplinary project, the development and implementation of which requires the involvement of specialists from different fields, therefore the project serves as an entry point for laboratories, research centers, departments, and industrial enterprises. 
The concept of entropy of behavior of an ecosystem $(E)$ is a category that allows describing the dependencies of actors included in its structure, since the entropy of connected processes converges when their connection is strengthened.

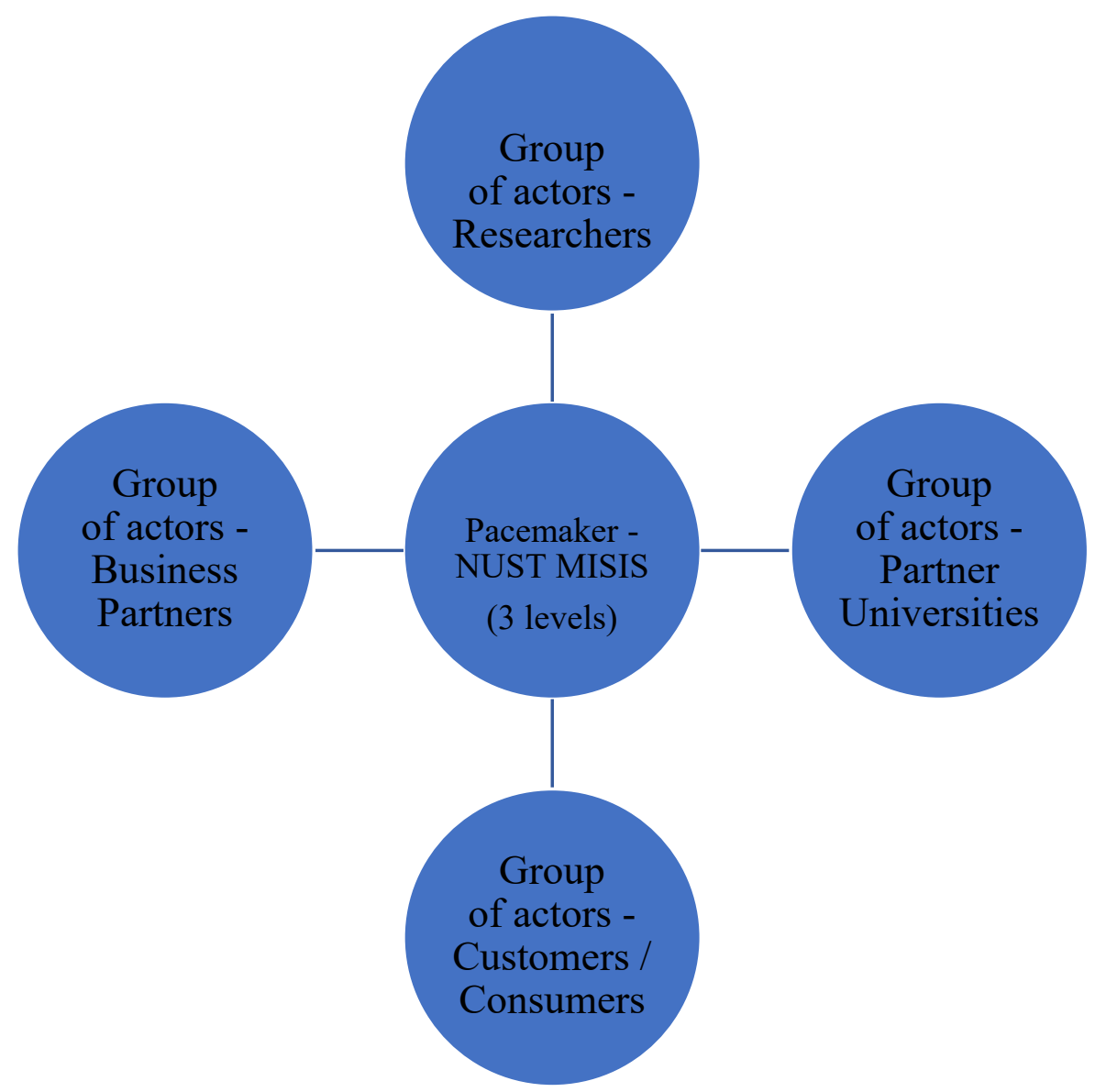

Figure 3. The structure of the ecosystem "Green technologies for resource conservation".

First, let us calculate the entropy indicator of the ecosystem behavior "Green technologies for resource conservation" based on the Shannon method (Formulas (5) and (6)) [45]. As a function $p$ (the ratio of the number of common goals of actors to the number of goals of the ecosystem), we will consider the probability of achieving the goals of the ecosystem by actors $\left(A_{i}\right)$. The $E\left(A_{i}\right)$ value is calculated by Formula (7):

$$
E\left(A_{i}\right)=-\left(0.5 \log _{2} 0.5+0.33 \log _{2} 0.33+0.17 \log _{2} 0.17\right)=1.46 .
$$

That is $E\left(A_{i}\right)>E_{p}$, therefore, the innovation ecosystem is characterized by weak sustainability. The greater flow of knowledge and information between actors leads to a lower level of entropy in the ecosystem. Thus, the entropy of the ecosystem and the degree (strength) of the connection of actors have an inverse relationship. It should be noted that with an increase in the degree of openness of an ecosystem, entropy decreases, and order is brought about not only in general but in all parameters just in only one indicator or system parameters.

Next, we assess the level and strength of connections between actors from different groups of the ecosystem. Evaluation of qualitative indicators characterizing the relationship between the actors of the ecosystem can be realized using a specially developed scale of expert assessments, normalized in the range from 0 to 5 . In the absence of reliable information on indicators, the assessment was carried out on a limited range of indicators. The reference gradation is defined as follows: 
- $0 \leq$ Independence of an actor of one group from an actor of another group $<1$.

- $1 \leq$ The relationship between actors is for informational purposes only $<2$.

- $2 \leq$ The dependence between the actors is partially project-based, resource balanced and intellectual $<3$.

- $\quad 3 \leq$ Project dependency $<4$.

- $4 \leq$ Complete resource and project dependence $<5$.

After receiving expert assessments in points, we determined the coded values of the control points $\left(y_{i j}\right)$ taking into account the lower and upper limits of the value $\left(y_{\min }=0, y_{\max }=5\right)$ according to the method of the desirability of Harrington [44] (Table 5).

Table 5. Harrington desirability scale.

\begin{tabular}{ccccc}
\hline $\begin{array}{c}\mathbf{( 1 . 0 0 - 0 . 8 0 )} \\
\text { «Very Good» }\end{array}$ & $\begin{array}{c}\mathbf{( 0 . 8 0 - 0 . 6 3 )} \\
\text { «Good» }\end{array}$ & $\begin{array}{c}\mathbf{( 0 . 6 3 - 0 . 3 7 )} \\
\text { «Satisfactorily» }\end{array}$ & $\begin{array}{c}\mathbf{( 0 . 3 7 - 0 . 2 0 )} \\
\text { «Bad» }\end{array}$ & $\begin{array}{c}\mathbf{( 0 . 2 0 - 0 )} \\
\text { «Very Bad» }\end{array}$ \\
\hline $\begin{array}{c}\text { Complete } \\
\text { resource and } \\
\text { project } \\
\text { dependence. }\end{array}$ & $\begin{array}{c}\text { Project } \\
\text { dependency. }\end{array}$ & $\begin{array}{c}\text { The dependence between } \\
\text { the actors is partially } \\
\text { project-based, resource } \\
\text { balanced and intellectual. }\end{array}$ & $\begin{array}{c}\text { The relationship } \\
\text { between actors is } \\
\text { for informational } \\
\text { purposes only. }\end{array}$ & $\begin{array}{c}\text { Independence of an } \\
\text { actor of one group } \\
\text { from an actor of } \\
\text { another group. }\end{array}$ \\
\hline
\end{tabular}

The bond strength of the actors is defined as the geometric mean of the coded values $\left(y_{i j} ; d_{i}\right)$. Calculate the encoded values of these breakpoints $\left(y_{i j}\right)$ and the coded value of the parameter is the dependence between the actors in Project 1. The calculation is done using Formulas (8) and (9):

$$
\begin{gathered}
y^{\prime}(1)=-\ln \ln (1 / 0.37)=0.00576 ; \\
y^{\prime}(10)=-\ln \ln (1 / 0.8)=1.4999 .
\end{gathered}
$$

The equation $y^{\prime}=a \times y+b$ acts as a translation mechanism $y$ to $y^{\prime}$. Values $a$ ub can be found through a system of equations: $(0.00576=a \times 1+b)$ and $(1.4999=a \times 10+b)$. In this way, $a=0.16576$ and $b=-0.16025$. The final equation becomes Formula (10):

$$
y^{\prime}=0.16576 y-0.16025 \text {. }
$$

Similarly, the parameter was estimated for Project 2 and Project 3. The generalized Harrington desirability function (optimization criterion) of the $j$-th actor is defined as the geometric mean of particular desirability [44]. The results are presented in Table 6.

Table 6. Interpretation of standard marks on the Harrington scale for ecosystem actors.

\begin{tabular}{cccccccc}
\hline \multirow{2}{*}{ Projects } & \multicolumn{2}{c}{$\begin{array}{c}\text { A Group of Actors- } \\
\text { Researchers }\end{array}$} & \multicolumn{2}{c}{$\begin{array}{c}\text { Group of } \\
\text { Actors-Partners }\end{array}$} & \multicolumn{2}{c}{$\begin{array}{c}\text { Customer Actor } \\
\text { Group }\end{array}$} & \multirow{2}{*}{$\begin{array}{c}\text { Harrington Generalized } \\
\text { Desirability Function (D) }\end{array}$} \\
\cline { 2 - 7 } & $\boldsymbol{y}_{i j}$ & $\mathbf{D 1}$ & $\boldsymbol{y}_{\boldsymbol{i j}}$ & $\mathbf{D} \mathbf{2}$ & $\boldsymbol{y}_{i j}$ & $\mathbf{D} 3$ & \\
\hline Project 1 & 1.486 & 0.797 & 1.251 & 0.751 & 1.331 & 0.768 & 0.82 \\
Project 2 & 1.135 & 0.725 & 0.864 & 0.656 & 1.378 & 0.780 & 0.71 \\
Project 3 & 1.123 & 0.684 & 0.756 & 0.598 & 1.154 & 0.723 & 0.59 \\
\hline
\end{tabular}

On the Harrington scale, Project 1 is categorized as "very good", hence the actors have full resource and project dependence. Project 2 is categorized as "good", which indicates that there is project dependence between the actors. In Project 3, the relationship between actors is purely informational. The integral indicator of the bond strength of the ecosystem actors was calculated using the Formula (11):

$$
D_{j}=\sqrt[3]{0.82 \times 0.71 \times 0.59}=0.698
$$


When the result is closer to 1 , then it is better for ecosystem sustainability. In our example, the indicator of the strength of connection was 0.698 , therefore, we can talk about the sustainability of the innovative industrial ecosystem "Green technologies for resource conservation".

This methodology for assessing the potential of projects allows making decisions on the further participation of actors in ecosystem projects.

\section{Conclusions}

This paper proposed a methodological framework for studying industrial ecosystems in the context of self-organization and sustainability perspective. The main research question was how to operationalize the processes of self-organization in the industrial ecosystem without an external governing body and to ensure ecosystem sustainability. To this end, the authors propose a new tool for estimating the actor's collaboration level based on the entropy approach Harrington method. It allows for operationalizing the processes of self-organization in the ecosystem without external intervention and addresses the main implications for the sustainability of industrial ecosystems. The authors illustrated their assumptions with an empirical case study of the industrial ecosystem "Green technologies for resource conservation", which is part of the National University of Science and Technology "MISIS" ecosystem. The propositions arising from this analysis provide information to help academics, policymakers, government, and individual enterprises with a more adequate understanding of the practical mechanisms and tools that help trigger the self-organization and sustainability of the innovation ecosystems. The proposed novel tool for assessing an actor collaboration level in the ecosystem makes a significant contribution to the industrial ecosystem theory and methodology development in terms of conceptualization of the self-organization and self-development processes and further investigation of their impact on ecosystem sustainability.

\section{Limitation and Future Research Directions}

We have developed a novel methodological framework for industrial ecosystem sustainability assessment with a focus on integration and collaboration effects. Meanwhile, the proposed approach has some shortcomings and limitations caused by them. The following main limitations should be mentioned: It is not applicable for scenario calculations, high volatility of estimates, problems of specification selection when choosing data sources, high susceptibility to the ranking method, and parameter values. We raise the following questions to be addressed as future lines of research. Firstly, it is necessary to develop the conceptual and methodological aspects of the correlation between the ecosystem's maturity and sustainability. Secondly, the authors plan to propose the model of ecosystem risks for industrial ecosystems economic security Thirdly, to further develop the theory of ecosystems on three levels-macro, meso, and micro.

Finally, it will be necessary to adopt a proposed methodology for assessing sustainability for different types of ecosystems (innovation, entrepreneurial, territorial, ext.) depending on the stage of the ecosystem's life cycle and to validate the theoretical foundations and propose an extended system of indicators for assessing the circular potential of actors in the industrial ecosystem. Currently, most authors use the same indicators to assess circularity for measuring sustainability. This makes it difficult to reveal the contribution of circular processes to the achievement of environmental/green goals.

Author Contributions: Conceptualization, T.T. and Y.V.; methodology, N.S. and V.P.; formal analysis, T.T., N.S., Y.V., and V.P.; investigation, T.T.; resources, N.S.; elaborated the literature review, T.T. and N.S.; writing-original draft preparation, T.T. and N.S.; writing-review and editing, T.T., N.S., Y.V., and V.P. All authors have read and agreed to the published version of the manuscript.

Funding: This research was funded by the RFBR grant No. 20-010-00470.

Conflicts of Interest: The authors declare no conflict of interest. 


\section{References}

1. Plotnikov, V.; Vertakova, Y.; Leontyev, E. Evaluation of the effectiveness of the telecommunication company's cluster management. Econ. Comput. Econ. Cybern. Stud. Res. 2016, 50, 109-118.

2. Vasin, S.; Gamidullaeva, L.; Tolstykh, T.; Rostovskaya, T.; Skorobogatova, V. From innovation system through institutional transformation to digital innovation ecosystem. In Proceedings of the 31st International Business Information Management Association Conference, IBIMA 2018: Innovation Management and Education Excellence through Vision, Milan, Italy, 25-26 April 2018.

3. Vertakova, Y.V.; Plotnikov, V.A. The Integrated Approach to Sustainable Development: The Case of Energy Efficiency and Solid Waste Management. Int. J. Energy Econ. Policy 2019, 9, 194-201. [CrossRef]

4. Koch, T.; Windsperger, J. Seeing through the network: Competitive advantage in the digital economy. J. Organ. Des. 2017, 6, 6. [CrossRef]

5. Porter, M.E. Clusters and the new economics of competition. Harv. Bus. Rev. 1998, 76, 77-90. [PubMed]

6. Richter, C.; Kraus, S.; Brem, A.; Durst, S.; Giselbrecht, C. Digital entrepreneurship: Innovative business models for the sharing economy. Creat. Innov. Manag. 2017, 26, 300-310. [CrossRef]

7. Taleb, N.N. Antifragile: Things That Gain from Disorder; KoLibri, Azbuka-Attikus: Moscow, Russia, 2014.

8. Moore, J.F. The Death of Competition: Leadership and Strategy in the Age of Business Ecosystems; Harper Collins: New York, NY, USA, 1997.

9. Jacobides, M.G.; Cennamo, C.; Gawer, A. Towards a theory of ecosystems. Strateg. Manag. J. 2018, 39, 2255-2276. [CrossRef]

10. Kleiner, G.B. Ecosystem economy: Step into the future. Econ. Revival Russ. 2019, 1, 40-45.

11. Sun, B.; Tang, J. Ecosystem health assessment: A PSR analysis combining AHP and FCE methods for Jiaozhou Bay, China. Ocean Coast. Manag. 2019, 1681, 41-50. [CrossRef]

12. Shvab, K. The Fourth Industrial Revolution. Available online: https://www.vedomosti.ru/economics/articles/ 2020/01/14/820569-davosskii-forum-manifest-biznesa (accessed on 12 June 2020).

13. Smorodinskaya, N.V. Network innovation ecosystems and their role in the dynamization of economic growth. Innovations 2014, 7, 27-33.

14. Karpinskaya, V.A. Ecosystem as a Unit of Economic Analysis. In Proceedings of the Second Conference of the Department of Modeling Production Facilities and Complexes of the Central Economics Institute of the Russian Academy of Sciences "Systemic Problems of Domestic Mesoeconomics, Microeconomics, Enterprise Economics", Moscow, Russia, 12 January 2018.

15. Lundvall, B.-A. National Systems of Innovation: Towards a Theory of Innovation and Interactive Learning; Frances Pinter: London, UK, 1992.

16. Freeman, C. The National System of Innovation in Historical Perspective. Camb. J. Econ. 1995, 19, 5-24.

17. Tolstykh, T.; Shmeleva, N.; Gamidullaeva, L. Evaluation of Circular and Integration Potentials of Innovation Ecosystems for Industrial Sustainability. Sustainability 2020, 12, 4574. [CrossRef]

18. Tolstykh, T.; Shmeleva, N.; Gamidullaeva, L.; Lapygin, Y. Regional Development in Russia: An Ecosystem Approach to Territorial Sustainability Assessment. Sustainability 2020, 12, 6424. [CrossRef]

19. Lenort, R.; Zapletal, F.; Wicher, P.; Shmeleva, N. Sustainability Development Goals Preferences in Metallurgical and Mining Industry. In Proceedings of the 29 International Conference in Metallurgy and Materials (METAL 2020), Brno, Czech Republic, 19-21 May 2020.

20. Brown, R.; Mason, C. Looking inside the spiky bits: A critical review and conceptualisation of entrepreneurial ecosystems. Small Bus. Econ. 2017, 49, 11-30. [CrossRef]

21. Etzkowitz, H.; Leydesdorff, L. The dynamics of innovation: From National Systems and "mode 2" to a Triple Helix of university-industry-government relations. Res. Policy 2000, 29, 109-123. [CrossRef]

22. Bruns, K.; Bosma, N.; Sanders, M.; Schramm, M. Searching for the existence of entrepreneurial ecosystems: A regional cross-section growth regression approach. Small Bus. Econ. 2017, 49, 31-54. [CrossRef]

23. Segura-Salazar, J.; Tavares, L.M. Sustainability in the Minerals Industry: Seeking a Consensus on Its Meaning. Sustainability 2018, 10, 1429. [CrossRef]

24. Adner, R.; Kapoor, R. Value creation in innovation ecosystems: How the structure of technological interdependence affects firm performance in new technology generations. Strateg. Manag. J. 2010, 31, 306-333. [CrossRef]

25. Sussan, F.; Acs, Z.J. The digital entrepreneurial ecosystem. Small Bus. Econ. 2017, 49, 55-73. [CrossRef] 
26. Meoli, M.; Paleari, S.; Vismara, S. The governance of universities and the establishment of academic spinoff. Small Bus. Econ. 2017, 52, 485-504. [CrossRef]

27. Ghio, N.; Guerini, M.; Lamastra-Rossi, C. The creation of high-tech ventures in entrepreneurial ecosystems: Exploring the interactions among university knowledge, cooperative banks, and individual attitudes. Small Bus. Econ. 2017, 52, 523-543. [CrossRef]

28. Oksanen, K.; Hautamäki, A. Transforming regions into innovation ecosystems: A model for renewing local industrial structures. Innov. J. Public Sect. Innov. J. 2014, 19, 5.

29. Adner, R. Match your innovation strategy to your innovation ecosystem. Harv. Bus. Rev. 2006, 84, 98-107.

30. Granstranda, O.; Holgerssonb, M. Innovation ecosystems: A conceptual review and a new definition. Technovation 2020, 90-91, 102098. [CrossRef]

31. Wareham, J.; Fox, P.; Lluís Cano Giner, J. Technology ecosystem governance. Organ. Sci. 2014, 25, 1195-1215. [CrossRef]

32. Lieder, M.; Rashid, A. Towards circular economy implementation: A comprehensive review in context of manufacturing industry. J. Clean. Prod. 2016, 115, 36-51. [CrossRef]

33. Carayannis, E.G.; Campbell, D.F.J. Knowledge Creation, Diffusion, and Use in Innovation Networks and Knowledge Clusters: A Comparative Systems Approach across the United States, Europe, and Asia; Praeger Publishers: Westport, CT, USA, 2016.

34. Jackson, D.J. What Is an Innovation Ecosystem? National Science Foundation: Arlington, VA, USA, 2011.

35. Kleyner, G.B. Industrial ecosystems: A look into the future. J. Russ. Econ. Revival 2018, 3, 53-62.

36. Yun, J.J.; Liu, Z. Micro- and Macro-Dynamics of Open Innovation with a Quadruple-Helix Model. Sustainability 2019, 11, 3301. [CrossRef]

37. Haken, G. Information and Self-Organization: A Macroscopic Approach to Complex Systems; Komkniga: Moscow, Russia, 2005.

38. Tiwana, A. Platform Ecosystems: Aligning Architecture, Governance, and Strategy; Murgan Kaufman Publishers: Burlington, MA, USA, 2013.

39. Prangishvili, I.V. Entropy and Other System Regularities: Issues of Managing Complex Systems; Nauka: Moscow, Russia, 2003.

40. Clarysse, B.; Wright, M.; Bruneel, J.; Mahajan, A. Creating value in ecosystems: Crossing the chasm between knowledge and business ecosystems. Res. Policy 2014, 43, 1164-1176. [CrossRef]

41. Vertakova, Y.; Plotnikov, V. Innovative and industrial development: Specifics of interrelation. Econ. Ann.-XXI 2016, 156, 37-40. [CrossRef]

42. Shmeleva, N. Innovation ecosystems in metallurgical industry: Evolution, measurements and trends. In Proceedings of the International Multidisciplinary Scientific GEO Conference Proceeding (SGEM 2018), Albena, Bulgaria, 2-8 July 2018.

43. Bailey, K.D. Social Entropy Theory; State University of New York Press: New York, NY, USA, 1990.

44. Harrington, E.C. The Desirability Function. Ind. Qual. Control 1965, 21, 494-498.

45. Shannon, C.E. Mathematical Theory of Communication. Available online: http://people.math.harvard.edu/ $\sim \mathrm{ctm} /$ home/text/others/shannon/entropy/entropy.pdf (accessed on 30 September 2020).

Publisher's Note: MDPI stays neutral with regard to jurisdictional claims in published maps and institutional affiliations.

(C) 2020 by the authors. Licensee MDPI, Basel, Switzerland. This article is an open access article distributed under the terms and conditions of the Creative Commons Attribution (CC BY) license (http://creativecommons.org/licenses/by/4.0/). 